Contract No. and Disclaimer:

This manuscript has been authored by Savannah River Nuclear Solutions, LLC under Contract No. DE-AC09-08SR22470 with the U.S. Department of Energy. The United States Government retains and the publisher, by accepting this article for publication, acknowledges that the United States Government retains a non-exclusive, paid-up, irrevocable, worldwide license to publish or reproduce the published form of this work, or allow others to do so, for United States Government purposes. 


\section{Development of Chemical Reduction and Air Stripping Processes to Remove Mercury from Wastewater}

A manuscript prepared for submittal to the American Society of Civil Engineers for publication in the Journal of Environmental Engineering.

Authors:

Dennis G. Jackson P.E. ${ }^{1}$

Brian B. Looney, Ph.D ${ }^{1}$

Robert R. Craig ${ }^{2}$

Martha C. Thompson ${ }^{2}$

Thomas F. Kmetz ${ }^{2}$

Affiliations:

(1) Savannah River National Laboratory

(2) Savannah River Nuclear Solutions LLC 
SRNL-STI-2013-00409

1 Development of Chemical Reduction and Air Stripping Processes to Remove Mercury from Wastewater 2

3 Dennis G. Jackson P.E. ${ }^{1}$

4 Brian B. Looney M.ASCE ${ }^{2}$

5 Robert R. Craig ${ }^{3}$

6 Martha C. Thompson ${ }^{4}$

7 Thomas F. Kmetz ${ }^{5}$

9 (1) Fellow Engineer, Savannah River National Laboratory, Building 773-42A, Aiken, South Carolina

10 29808, USA. E-mail: dennis.jackson@srnl.doe.gov (corresponding author)

11 (2) Environmental Research Engineer, Savannah River National Laboratory, Building 773-42A, Aiken, 12 South Carolina 29808, USA

13 (3) Principle Engineer, Savannah River Nuclear Solutions LLC, Building 730-4B, Aiken, South 14 Carolina 29808, USA

15 (4) Principle Engineer, Savannah River Nuclear Solutions LLC, Building 735-B, Aiken, South Carolina 16 29808, USA

17 (5) Project Manager, Savannah River Nuclear Solutions LLC, Building 730-4B, Aiken South Carolina 18 29808, USA

\section{Abstract}

21 This study evaluates the removal of mercury from wastewater using chemical reduction and air stripping 22 using a full-scale treatment system at the Savannah River Site. The existing water treatment system 23 utilizes air stripping as the unit operation to remove organic compounds from groundwater that also 24 contains mercury ( $\mathrm{C} \sim 250 \mathrm{ng} / \mathrm{L})$. The baseline air stripping process was ineffective in removing 25 mercury and the water exceeded a proposed limit of $51 \mathrm{ng} / \mathrm{L}$. To test an enhancement to the existing 26 treatment modality a continuous dose of reducing agent was injected for 6-hours at the inlet of the air 27 stripper. This action resulted in the chemical reduction of mercury to $\operatorname{Hg}(0)$, a species that is removable 28 with the existing unit operation. During the injection period a 94\% decrease in concentration was 29 observed and the effluent satisfied proposed limits. The process was optimized over a 2-day period by 30 sequentially evaluating dose rates ranging from $0.64 \mathrm{X}$ to $297 \mathrm{X}$ stoichiometry. A minimum dose of $16 \mathrm{X}$ 31 stoichiometry was necessary to initiate the reduction reaction that facilitated the mercury removal. 
SRNL-STI-2013-00409

1 Competing electron acceptors likely inhibited the reaction at the lower doses, which prevented removal

2 by air stripping. These results indicate that chemical reduction coupled with air stripping can effectively treat large-volumes of water to emerging part per trillion regulatory standards for mercury.

Headings: Mercury; Pollutants; Permits; Waste Treatment Plants; Chemical treatment; Volatilization;

\section{Introduction}

9 In recent years policies have been formulated and modified to decrease mercury discharges to the environment. The overall objective of these decreases is to reduce mercury exposure to the general

11 population from fish consumption. An illustration involves the Great Lakes Initiative (US EPA 1995 \&

12 2000) where water quality criteria for total mercury were established for both the protection of human 13 activities and for the protection of aquatic life (12 to $50 \mathrm{ng} / \mathrm{L}$ ) for all discharges to the Great Lakes 14 Basin. Subsequently the Methylmercury Fish Tissue Criterion (US EPA 2001) supported a compound 15 specific ambient water quality criteria (AWQC) for methylmercury (0.3 mg/kg) based upon fish tissue 16 wet weight rather than traditionally used ambient water column value (US EPA 1994). Later specific guidance (US EPA 2010) was provided for adoption of water quality standards incorporating water column criteria, monitoring and assessment through water column analysis, and achievement using total maximum daily loads (TMDL) that incorporate water column conditions. These dynamic policies regarding mercury have direct impact to industry, municipalities, and federal agencies. Liquid effluents

21 from these entities are subjected to discharge criteria that are derived from current water quality 22 standards.

For industrial effluents the National Pollutant Discharge Elimination System (NPDES) establishes discharge specific criteria necessary to meet water quality standards. As directed by the Clean Water Act the NPDES permit program controls water pollution by regulating point sources that discharge pollutants into waters of the United States. As discharge criteria change new water treatment approaches are needed to support reasonable implementation of the reduction programs. For industrial viability, these approaches must have the capacity to treat large volumes of water containing trace levels 31 removal techniques. 
2 A 2007 synopsis on the state of treating mercury in environmental media (US EPA, 2007) identifies several baseline technology classes for the treatment of mercury in water/wastewater. This summation also provides information on the number of case study deployments. The baseline technology classes include: 1) precipitation/co-precipitation (11 deployments), 2) adsorption (6 deployments), 3) membrane filtration (1 deployment) and 4) biological treatment (2 deployments). For full-scale applications, precipitation/co-precipitation was the most frequently used treatment process identified. When selected, adsorption based systems were generally used as a polishing technology utilizing activated carbon based media. Membrane filtration and bioremediation were the least frequently used technologies, with bioremediation limited to pilot-scale investigations. In a review of heavy metal removal methods, Fu and Wang (2011) extended the list of baseline technology classes to include electrochemical treatment.

US EPA (2007) identified innovative and emerging technologies, highlighting the results of Looney and others (2003) on chemical reduction and air stripping. The investigation by Looney et al. (2003) documented air stripping as a simple "alternative" treatment method for the removal of mercury from water and wastewater. The basis of the process involves the chemical reduction of dissolved phase mercury, $\mathrm{Hg}(\mathrm{II})$, to elemental mercury, $\mathrm{Hg}(0)$, using a reducing agent. In the elemental state mercury is volatile and can be effectively removed from water using air stripping. Chemical reduction and sparging of mercury is an integral component of Method 1631E (US EPA 2002). This method is for the determination of total mercury in aqueous samples in the range of $0.5-100 \mathrm{ng} / \mathrm{L}$. Under this method aqueous samples are first oxidized with bromine monochloride to destroy organic mercury complexes, then sequentially reduced with hydroxylamine hydrochloride to destroy free halogens, and finally reduced using stannous chloride. The final reduction step converts inorganic Hg(II) to volatile elemental mercury, $\mathrm{Hg}(0)$. Under Method 1631E the $\mathrm{Hg}(0)$ is separated from the solution using either a bubbler or flow-injection system with an inert gas to collect the mercury onto a gold trap. The analysis involves the thermal desorption of mercury from the gold trap using a cold-vapor atomic fluorescence spectrometer. With three reagent treatments prior to separation from the water phase, the complexity and efficacy of implementing air stripping for treatment is highly dependent upon the mercury species present within 
1 The work of Looney and others (2003) expanded upon earlier work that evaluated the use of stannous 2 chloride to remove mercury from a spring-fed source (Outfall 51) within the Y-12 Complex at Oak 3 Ridge (Lockhead Martin Inc., 1996). This investigation used a pilot scale (10 gpm) air stripper to 4 evaluate the stannous chloride treatment scheme. The investigation determined that approximately $80 \%$ 5 of the mercury in the source water was reactive with stannous chloride. The study explored various oxidants to convert the balance of the mercury to a tin reduceable form. The investigators concluded that none of the conventional oxidizing agents examined were effective at environmentally acceptable concentrations. A subsequent investigation (Klasson et al. 2003) reports the use of ozone/UV systems as a precursor to convert the mercury in this water so that it will readily react with the stannous chloride.

11 The Y-12 pilot test (Lockhead Martin Inc., 1996) demonstrated that a 3-4X stoichiometric excess of stannous chloride was effective in removing nearly $100 \%$ of the reactive mercury at air to water ratios greater than 13X. The study indicated that stannous chloride solutions in the feed reservoir were unstable in the presence of sunlight and oxygen. Ascorbic acid (Vitamin C) was identified as an effective preservative and proposed a concentrated ( $>1 \mathrm{~g} / \mathrm{L}$ ) stock solution prepared with oxygen-free water to increase stability. Southworth (2009) postulates on the role photochemical reactions may have in the stannous chloride treatment scheme. These observations are based upon effective applications in enclosed groundwater systems (Outfall 51) versus ineffective applications in open, exposed surface water (Outfall 200) sources within the Y-12 Complex. To further investigate this aspect stannous chloride was introduced along with sodium thiosulfate to the subterranean piping system immediately upstream of the where the Outfall 200 water emerges into an open channel. The sodium thiosulfate was incorporated to remove latent total residual chlorine. This test relied upon turbulent flow to provide mixing and resulted in a 33\% conversion of the baseflow $\mathrm{Hg}(\mathrm{II})$ (Southworth et al. 2009). Subsequent experiments targeting Outfall 200 investigated potential enhancements including the use of alternate dechlorinating reagents, alternate stabilizing agents for the stannous chloride solution, and alternate reducing agents other than stannous chloride (Southworth et al. 2010).

Looney and others (2003) performed a series of experiments to determine the efficacy of stannous chloride reduction alone for water treatment applications. Looney performed a series of batch tests 30 (vessel size $=500 \mathrm{ml}$ ) using raw and "conditioned” groundwater from the Savannah River Site to 31 evaluate the dose of stannous chloride on various sample matrices (wastewater feed stocks). This study 
1 evaluated mercury removal in stoichiometric ratios up to 5,040,000X and determined that stoichiometric

2 doses in the range of 5 to $25 \mathrm{X}$ were sufficient for relatively complete removal. A kinetic evaluation was also performed (Looney et al. 2003) to assess sparging rate on removal effectiveness. The kinetic study concluded that the air to water ratio controlled the removal rate and that the reduction-oxidation reaction

5 kinetics were not the rate-limiting step.

The previous investigations at both Savannah River and Oak Ridge provided critical information on technical viability, information on stoichiometric ranges, insight on rate-limiting processes, and the role that competing electron acceptors can have. Additional demonstration and testing is required for fullscale implementation and regulatory acceptance. Included within this is full-scale testing using

11 conventional treatment equipment.

\section{Groundwater Treatment System}

13 The Savannah River Site (SRS) operates an air stripper that is permitted as a Clean Water Act 14 wastewater treatment plant (SCDHEC Wastewater Construction/Operation Permit \#10,253). Discharge 15 of treated wastewater from this system is regulated through NPDES (SCDHEC Permit \#SC0000175). 16 The groundwater treatment system consists of a network of groundwater recovery wells and an air 17 stripper. This system has been in operation since 1985 as part of a RCRA corrective action to remove 18 chlorinated solvents, primarily PCE and TCE, from groundwater. In addition to contaminated groundwater the treatment system receives wastewater from an in-situ thermal treatment system that targets a DNAPL source zone.

The inlet groundwater to the air stripper contains mercury on the order of $250 \mathrm{ng} / \mathrm{L}$. This level exceeds a proposed NPDES limit of $51 \mathrm{ng} / \mathrm{L}$ (monthly average) and $140 \mathrm{ng} / \mathrm{L}$ (daily maximum) for the receiving outfall. Currently air stripping alone is ineffective in removing mercury from the treated effluent. The nominal wastewater flow to the air stripper is 1,609 lpm (425 gpm) that increases to 1,968 lpm (520 gpm) with contributions from the thermal treatment system. Airflow is maintained at a constant rate of 56,634 lpm (2,000 cfm), providing a nominal air to water ratio of 31:1.

The air stripper is a counter-current, packed column configuration (Kavanaugh and Trussell 1980; Treybal 1980; Montgomery 1985) with an internal volume of 23,280 liters (6,150 gallons). The design 31 incorporates upper and lower beds 5.8-m (19-ft) and 5.2-m (17-ft) long, respectively, that contain loose, 
1 random packed plastic saddles. Wastewater sample ports are located at the inlet, the top of the first packed bed, between the two packed beds, and at the discharge of the second packed bed. Figure 1 provides a schematic of the system illustrating sample locations and relevant water quality parameters.

During normal operations mercury at the inlet is on the order of $250 \mathrm{ng} / \mathrm{L}$ and increases with episodic contributions from the thermal treatment system. While mercury has not been explicitly identified as a known contaminant, historical releases of small quantities from process operations were likely. When small quantities of mercury were released with large quantities of traditional DNAPLs, non-traditional transport and release mechanisms are likely (Jackson et al. 2006). As DNAPL source zones are removed the mercury, which was partitioned within the non-aqueous phase prior to remediation, becomes available for recovery via the existing pump \& treat system.

\section{Mercury Removal Process}

13 Mercury removal from the wastewater involves the chemical reduction of $\mathrm{Hg}(\mathrm{II}) \operatorname{to~} \mathrm{Hg}(0)$ followed by 14 volatilization to the air phase. Chemical reduction is promoted by the addition of stannous chloride that 15 acts as a reducing agent. For describing this treatment modality the following half-reactions are used to develop the oxidation-reduction equation (Lide, 2000):

$$
\begin{array}{ll}
\mathrm{Hg}^{+2}+2 \mathrm{e}^{-}=\mathrm{Hg}^{0} & \mathrm{E}_{0}=+0.851 \\
\mathrm{Sn}^{+4}+2 \mathrm{e}^{-}=\mathrm{Sn}^{+2} & \mathrm{E}_{0}=+0.151
\end{array}
$$

These half-reactions are combined to develop the following equation that governs the treatment process:

$$
\mathrm{Hg}^{+2}+\mathrm{Sn}^{+2}=\mathrm{Hg}^{0}+\mathrm{Sn}^{+4} \quad \mathrm{E}_{0}=+0.700
$$

As written the reaction is spontaneous and under ideal conditions a 1:1 stoichiometric ratio exists between the reducing agent and the oxidized species. Stannous chloride dihydrate [CAS \#10025-69-1] is

$$
\mathrm{HgCl}_{2}{ }^{0}+\mathrm{SnCl}_{2} \cdot 2 \mathrm{H}_{2} \mathrm{O}=\mathrm{Hg}(0)+\mathrm{SnO}_{2}(\mathrm{~s})+4 \mathrm{Cl}^{-}+2 \mathrm{H}_{2} \mathrm{O}
$$


SRNL-STI-2013-00409

2 In this equation mercury chloride is identified as the mercury source based upon the thermodynamically

3 favored species in wastewater.

5 Inherit in the treatment process is the ability to readily remove the elemental mercury during the air stripping process. Henry's constant provides information on the partitioning of a compound between the air and water phase (Schwarzenbach at.al, 1993). Air stripping is considered a practicable treatment process for compounds having a Henry’s constant greater than 10 atm-L/mol (FTRT, 2002). Henry’s constant for mercury was determined based upon the relationship between vapor pressure and aqueous solubility (Schwarzenbach et al., 1993) and is presented in Table 1. As shown the Henry’s constant for

11 mercury is determined to be $8.7 \mathrm{~atm}-\mathrm{L} / \mathrm{mol}$ and is at the lower end of the applicable range based upon 12 the guidance document. The treatment method does introduce inorganic tin and chloride to the effluent. 13 However when modest doses of reagent are applied the levels of these compounds are below AWQC 14 thresholds.

\section{Experimental Methods}

16 The full-scale effectiveness of the treatment process was evaluated as a "Technical Demonstration" under the existing wastewater permit for the air stripper described earlier. A feasibility test was first performed to determine full-scale viability and was followed by a variable dose-response test. These results are used to evaluate the effectiveness of each dose and will serve as a basis for identification of operating conditions for full-scale implementation.

\section{Feasibility Testing}

22 Feasibility testing consisted of injecting a reducing agent at the inlet of the air stripper for a period of 6hours. Previous batch tests (Looney, et al. 2003) had demonstrated stoichiometric ratios in the range of 5 to $25 \mathrm{X}$ as sufficient for relatively complete mercury removal. Based upon these observations a $25 \mathrm{X}$ dose of reducing agent was selected. This level would reduce uncertainties related to potential inadequate mixing, incomplete chemical reduction (contact time), and competing electron acceptors that were considered as possibilities with full-scale implementation. Prior to, during, and following injection wastewater samples were collected for analysis from the inlet, mid-column, and discharge of the air stripper. The reducing agent consisted of an acidified solution of tin(II) chloride dihydrate (MW = 
1 225.65). The solution was prepared by dissolving 5.86 grams of reagent grade tin(II) chloride dihydrate

2 [CAS \#10025-69-1] in 10-ml of reagent grade hydrochloric acid [CAS \#7647-01-0] and diluting to

311 liters using 10-18 M $\Omega$-cm Type 1 reagent grade water. Prior to dilution the reagent water was

4 sparged with mercury-free nitrogen to remove dissolved oxygen as described in EPA Method 1631E.

5 This solution was injected using a high-pressure peristaltic pump (Masterflex L/S Pump Drive (Model 7523-50) and High Performance Pump Head (Model 77250-62) equipped with L/S 16HP PharMed tubing. To provide adequate mixing the injection point utilized an injection quill (Primary Fluid Systems Model IQ-58-PVDF) installed in a downstream static pressure port of a flow-restricting orifice.

Prior to injection three wastewater samples were collected, including one sample that was collected

11 approximately 24-hours prior to injection. Six wastewater samples were collected at hourly intervals during injection, and three samples were collected after injection, including one sample that was collected 24-hours after injection. Wastewater samples were collected using ambient water quality trace metals sampling techniques (EPA Method 1669). A certified contract laboratory provided total mercury analysis (EPA Method 1631E).

\section{Dose-Response Testing}

17 Dose-response testing was performed to determine the necessary dose to promote chemical reduction

18 and removal of mercury. During this test an acidic solution of stannous chloride dihydrate [CAS \#10025-69-1] was injected into the inlet of the air stripper. The concentration and the injection rate of the reagent were systematically adjusted to evaluate effectiveness at various dose rates. A total of nine dose rates were evaluated between 0.27 and $133 \mathrm{mg} / \mathrm{min}$ of reagent. The minimum dose rate is below the ideal stoichiometry described by Equation (2) and the maximum is an order of magnitude greater than that used during the feasibility test. The dose rate and injection parameters are presented in Table 2. As illustrated in this table the dose rate for each subsequent run was approximately twice that of the previous run. The stannous chloride solution was prepared by dissolving an appropriate mass of reagent grade tin(II) chloride dihydrate in concentrated hydrochloric acid and diluting to 7.5 liters (1.98 gallons) with mercury-free water as described earlier. For Runs \#1 through \#8 this provided sufficient stock to support two treatment levels per reagent batch by simply changing the injection flow rate. The injection flow rate was controlled using the high-pressure peristaltic pump, pump head and tubing previously described. The pump system is capable of delivering flow rates in the range from $0.9 \mathrm{ml} / \mathrm{min}$ to 90 $\mathrm{ml} / \mathrm{min}$ with discharge pressure of $100 \mathrm{psig}$. 
2 Testing for each dose factor consisted of applying the prescribed dose rate (Table 2) for an equilibrium period of approximately 90 minutes followed by sample collection. Assuming a conservative residence time distribution of 12.3 minutes (based upon a flooded column volume of 6,150 gallons) the equilibrium period corresponds to a minimum of 4 residence times. Following the equilibrium period three sets of wastewater samples were collected (EPA Method 1669) at 10 to 15 minute intervals from the inlet, top, mid-column, and discharge of the air-stripper and analyzed for total mercury (EPA Method 1631E). Following sample collection the dose factor was increased and the equilibrium period and sampling activities repeated for all treatment levels.

\section{Results}

\section{Feasibility Testing}

During the feasibility test 7.2 liters (1.9 gallons) of tin(II) chloride dihydrate (2.36 mM/L) was injected as a reducing reagent for 325 minutes. This corresponds to an applied dose rate of $11.8 \mathrm{mg} / \mathrm{min}$ of reagent, 25X the stoichiometric amount. During the injection period steady-state flow conditions were maintained $\left(Q_{\text {water }}=1,741 \mathrm{lpm}(460 \mathrm{gpm}), \mathrm{Q}_{\text {air }}=56,685 \mathrm{lpm}(2001.8 \mathrm{cfm})\right.$, air:water $\left.=32.6: 1\right)$. The system variables (Figure 1) were maintained during testing by receiving wastewater only from the groundwater recovery wells. A total of 36 wastewater samples were collected and analyzed for total mercury. During the test the concentration of mercury (mean $\pm 95 \%$ confidence interval) at the inlet (pre + injection + post) was $\mathrm{C}_{0}=233 \pm 12.2 \mathrm{ng} / \mathrm{L}(\mathrm{n}=12)$. During the injection period total mercury decreased from $248 \pm 13.5 \mathrm{ng} / \mathrm{L}(\mathrm{n}=5)$ at the inlet to $14.1 \pm 1.9 \mathrm{ng} / \mathrm{L}(\mathrm{n}=5)$ at the outlet, a decrease of 94\%. Following the injection period, mercury in the effluent increased to $190 \pm 31.1 \mathrm{ng} / \mathrm{L}$ (n=3), within $15 \%$ of the observed inlet value during the sampling event. The concentration at the mid-column increased to $116 \pm 22.5 \mathrm{ng} / \mathrm{L}(\mathrm{n}=3)$.

Figure 2 provides insight on the kinetics of the chemical reactions by examining the concentration of mercury at the inlet, mid-column, and outlet as a function of time. Injection of the reducing agent began at $\mathrm{t}=00: 00,10$-minutes after injection the concentration at the mid-column had decreased $86 \%$ to $31.5 \mathrm{ng} / \mathrm{L}$ while the concentration at the outlet had only decreased $19 \%$ to $186 \mathrm{ng} / \mathrm{L}$. After 70 minutes of injection, the concentration at both the mid-column and outlet reached steady state and remained 
1 constant for the injection period, mid-column $=3.6 \pm 0.50 \mathrm{ng} / \mathrm{L}(\mathrm{n}=5)$ and outlet $=14.1 \pm 1.91 \mathrm{ng} / \mathrm{L}$

2 ( $n=5)$. These results indicate that the system reaches steady state approximately one hour after injection 3 begins.

During the collection of samples from the mid-column particulate matter was identified. The particulate matter is associated with precipitation and dislocation of minerals to/from the packing material of the air stripper. Previous sampling at the discharge targeted particulate material and indicated that the material contained mercury on the order of $1-3 \mathrm{mg} / \mathrm{kg}$. Upon discovery the analytical laboratory was requested to filter all samples associated with the mid-column location upon arrival. The laboratory was able to filter eleven of the twelve samples. The one unfiltered sample was collected during the pre-injection period

$11(\mathrm{t}=-24: 10)$ and had a total mercury concentration of $603 \mathrm{ng} / \mathrm{L}$. The value was rejected at the $99 \%$ 12 confidence level $\left(\mathrm{r}_{11}=0.814, \mathrm{r}_{\text {crit }}=0.677\right)$ from the pre-injection population $(\mathrm{n}=9)$ using Dixon's " $\mathrm{Q}$ ” 13 parameter (Rorabacher, 1991).

\section{Dose-Response Testing}

15 Dose response testing was performed over a two-day period under constant operational conditions $\left(\mathrm{Q}_{\text {water }}=1,613 \mathrm{lpm}(426 \mathrm{gpm}), \mathrm{Q}_{\text {air }}=56,662 \mathrm{lpm}(2001 \mathrm{cfm})\right.$, air: water = 35.1:1). Dose-response testing was performed with wastewater only from the groundwater recovery wells. A total of 108 wastewater samples were collected and analyzed for total mercury using the identified methods. During this test the dose rate of the reagent was incrementally increased from $0.27 \mathrm{mg} / \mathrm{min}$ to $133 \mathrm{mg} / \mathrm{min}$. A total of nine different dose rates were investigated. For each treatment level three wastewater samples were collected from four locations: inlet, top of the column, middle of the column, and the outlet/discharge. Previous sampling activities at the mid-column had identified particulate matter associated with the samples. To minimize the amount of particulate material, samples at the top- and mid-column were collected using a 500-ml polypropylene filter flask (Fisher P/N 10-182-50A with Teflon FEP tubing) to remove solid particles. A dedicated sampling system was used for each location.

The results (mean $\pm 95 \%$ confidence interval) from the sampling are presented in Figure 3 as a function of the stoichiometric dose factor, defined as the molar ratio of reducing agent to total mercury. During the dose-response test total mercury at the inlet was $\mathrm{C}_{0}=238.9 \pm 2.47 \mathrm{ng} / \mathrm{L}(\mathrm{n}=27)$. As indicated in Figure 3, treatment levels below a dose factor of 10X had minimal effect on the concentration of mercury in the system. Treatment levels above a 10X dose factor exhibited sizeable decreases in total 
1 mercury at both the mid-column and the discharge positions. Observations indicate that a minimum dose of $6.65 \mathrm{mg} / \mathrm{min}$ (16X stoichiometry) is necessary to promote the removal of mercury from the system (91\%). A dose rate of $13.3 \mathrm{mg} / \mathrm{min}$ (30X stoichiometry) resulted in removal of $95 \%$ of the mercury. Subsequent increases in dose above 30X stoichiometry did not further decrease effluent concentration.

\section{Discussion}

6 During the feasibility test a 25X stoichiometric dose of stannous chloride was demonstrated to be 7 effective in removing mercury from the wastewater. During the injection period the concentration of mercury decreased $94.3 \%$ across the column of the air stripper. The difference in concentration observed between the inlet and outlet during the injection period was determined to be statistically significant

$10\left(\mathrm{p}=10^{-5.98}\right)$. The decrease in concentration is judged to be from the chemical reduction and

11 volatilization of the mercury from the wastewater. Once injection of stannous chloride was terminated

12 the concentration of mercury increased at both the mid-column and outlet locations.

14 The results from the inlet and outlet demonstrate the effectiveness of the treatment modality from a unit operation perspective. Results from the mid-column provide insight on internal processes and the role that the packing has as both a source and a sink within the system. The following observations from Figure 2 are identified as indicators that demonstrate this role: 1) During the injection period the concentration of mercury at the outlet is significantly greater at the mid-column $(14.1 \mathrm{ng} / \mathrm{L}>3.6 \mathrm{ng} / \mathrm{L}$, $\left.\mathrm{n}=5, \mathrm{p}=10^{-3.84}\right), 2$ ) following the injection period the concentration of mercury at the mid-column is significantly less than the inlet (116 ng/L $\left.<224 \mathrm{ng} / \mathrm{L}, \mathrm{n}=3, \mathrm{p}=10^{-3.04}\right)$, and 3) also following the injection period the concentration of mercury at the outlet is significantly greater than at mid-column (190 ng/L > $116 \mathrm{ng} / \mathrm{L}, \mathrm{n}=3, \mathrm{p}=10^{-2.16}$ ). These observations illustrate the complex and dynamic processes internal to the system that integrate redox reactions and partitioning coefficients. While this internal integration results in the effective removal of mercury by the unit operation, understanding these processes and the role of chemical partitioning in the vapor, aqueous, and solid phase provides information necessary for predictable and reliable operation.

Under baseline operations (prior to feasibility testing), mercury enters and exits the system in the wastewater as an aqueous species, $\mathrm{Hg}(\mathrm{II})_{\mathrm{aq}}$. Under these conditions mercury species are driven towards equilibrium between the aqueous and the solid phases, specifically the internal packing. This chemical 
1 driving force results in the mass transfer of mercury from the wastewater to the packing and

2 accumulated coatings resulting in an accumulation of mercury within the system. This is demonstrated

3 from the chemical analysis (EPA Method 7471) of packing material collected prior to testing but after

4 several years of operation. This analysis identified the mercury content of the packing and internal

5 coatings to be $1.54 \mathrm{mg} / \mathrm{kg}$.

During the injection period the reducing agent, $\mathrm{Sn}(\mathrm{II})_{\mathrm{aq}}$, promotes the rapid chemical reduction of $\mathrm{Hg}(\mathrm{II})_{\text {aq }}$ species in the inlet wastewater. Once reduced to $\mathrm{Hg}(0)$, air to water partitioning (Henry's Law) results in removal of mercury from the system in vapor phase. This was demonstrated previously (Looney et al. 2003) and is supported by the observations currently presented. The first indicator of the

11 internal dynamics unique to the full-scale system relates to the increase in concentration observed between the mid-column and the outlet during reagent injection. A mass balance between these stations indicates that the loading rate of mercury to the wastewater is $18.3 \mu \mathrm{g} / \mathrm{min}$ from the lower bed during the injection period. This loading is considered to be associated with desorption of mercury that accumulated in the packing material prior to testing.

Also present during the injection period of the feasibility test is an excess amount of $\mathrm{Sn}(\mathrm{II})_{\mathrm{aq}}$ and the oxidized Sn(IV)s species. While both species exit the system in the aqueous phase there is also a driving force for these species to equilibrate with the packing material. We postulate that during reagent injection, some amount of the excess Sn(II) $)_{\text {aq }}$ accumulates within the system. Evidence of this

Following the injection of $\mathrm{Sn}(\mathrm{II})_{\mathrm{aq}}$ recovery to baseline conditions begin. During the transitional period internal processes associated with the packing material result in different responses at the inlet, the midcolumn, and outlet positions. The differentials observed between positions demonstrate the internal dynamic transition as the system returns to baseline conditions. This transition period includes a reversal of mass transfer such that the packing acts as a reservoir for the compounds present. The second indicator of the complex internal processes is observed with the incomplete recovery of mercury at the mid-column. Based on the rebound data (Figure 2), mercury is removed from the wastewater by the upper bed at the rate of $188 \mu \mathrm{g} / \mathrm{min}$ following the injection period. Based upon previous observations of mercury accumulation in the packing a fraction of this removal can be attributed to solid phase 
1 partitioning. We also support the concept that excess Sn(II) also accumulates in the packing during

2 injection and then desorbs to reduce a portion of the $\mathrm{Hg}(\mathrm{II})_{\mathrm{aq}}$ entering the system.

4 The third indicator of the complex internal processes relates to the significant increase in mercury

5 observed across the lower bed (between the mid-column and the outlet) and definitively demonstrates that a latent source of mercury remained following the feasibility test. Based upon average concentrations following the injection period, the flux from the lower bed to the wastewater is

$8129 \mu \mathrm{g} / \mathrm{min}$.

There are several internal variables that were not quantified in this investigation that preclude a more detailed analysis of the internal processes of the system, the most significant relates to concentrations of mercury and tin in solid phase during the injection and recovery periods. Detailed information on these variables and sorption kinetics of the packing material would provide important data for long-term operations. It is very likely that excess reagent during injection partially removed latent mercury from the system under injection. Logically this removal would have occurred first in the upper bed and then in the lower bed. Future research efforts should focus on the packing material and accumulation rates of compounds during operation. We note that in the six weeks between the feasibility test and the doseresponse test the system returned to baseline conditions.

During the dose-response test, the difference in means between the inlet and outlet for each treatment were significantly heterogeneous (one-way anova, $\mathrm{F}_{8,18}=2,523.5, \mathrm{P}=10^{-25.1}$ ). Pairwise comparison within groups (Tukey-Kramer, MSD $=11.48, \mathrm{p}<0.05$ ) was used to distinguish effective and ineffective treatments (Figure 4). Ineffective treatment occurred at dose rate of 6.3X and below and effective treatments occurred at a dose rate of $16 \mathrm{X}$ and above. The threshold in effective dose is associated with competing electron acceptors in the wastewater, including dissolved oxygen and possibly volatile organic compounds. Dissolved oxygen is present in the inlet wastewater $(\mathrm{DO}=6.6 \mathrm{mg} / \mathrm{l})$ and is also introduced during the stripping process and organic constituents TCE and PCE are present in the inlet wastewater in excess of $2.0 \mathrm{mg} / \mathrm{L}$ (Figure 1). Historical removal rates of the volatile constituents exceed 99.95\% for this system. During dose response testing the removal rate exceeded this threshold with rates generally greater than $99.99 \%$ for both TCE and PCE. Effluent results were generally at or below the detection limit for the organic constituents. The low organic concentrations $(<1 \mu \mathrm{g} / \mathrm{L})$ in the effluent 
1 precludes a rigorous analysis of any organic + reagent reactions during dose-response testing. While

2 alternate gases (i.e. nitrogen, carbon dioxide, or inert gas) are viable to reduce interferences from oxygen, for most applications the use of atmospheric air has the lowest long-term operations and maintenance costs. It is noted that when dose-rates at or above $16 \mathrm{X}$ were applied, mercury in ng/L range were effectively removed in the presence of known (dissolved oxygen) and potential (TCE and PCE) electron acceptors in concentrations several orders of magnitude higher. These observations are consistent with those from the previous investigation (Looney et al., 2003).

During the dose-response test concentrations observed at the mid-column and outlet locations were consistent with each other. The agreement in concentration is attributed to the use of increasingly higher

11 dose-rates that likely resulted in the removal of any latent mercury within the system. As indicated in

12 Figure 3, as the dose rate is increased in Treatments \#6 through \#9, no differential in concentration

13 between the mid-column and the outlet are observed. It is likely that a short application of stannous 14 chloride at a high dose would remove any latent mercury internal to the system.

Based upon the observations presented a reagent dose rate of $12-14 \mathrm{mg} / \mathrm{min}$ is recommended for initial operations of this system. This dose rate represents 25-30X the amount of reagent required based upon the observed inlet parameters $\left(\mathrm{Q}=425 \mathrm{gpm}, \mathrm{C}_{0}=240 \mathrm{ng} / \mathrm{L}\right)$ and conditions. The recommended dose should provide sufficient reagent to overcome competing electron acceptors and remove mercury from the wastewater examined. When this process is considered for other wastewater sources laboratory studies are recommended prior to full-scale implementation. EPA Method 1631E identifies three sequential chemical treatments prior to sparging to assure complete recovery of all mercury species prior to quantification. During an earlier investigation (Southworth 1996) found that stannous chloride alone was only effective at removing $80 \%$ of the total mercury from the water, which was attributed to the presence of other "refractory" species. For our application a sufficient dose can be delivered to promote removal so that the effluent wastewater is below current regulatory thresholds.

\section{Conclusions}

28 The feasibility test demonstrated that stannous chloride injection is effective in removing mercury using 29 conventional air stripping processes. An applied dose of 25X stoichiometry caused the chemical reduction of mercury and subsequent removal via air stripping. Dose response testing determined that 
SRNL-STI-2013-00409

1 dose requirements are dependent upon competing electron acceptors and that a dose of 16X

2 stoichiometry or greater is needed to facilitate removal within the system investigated. The results

3 demonstrated that the treatment modality is effective in decreasing mercury to the 5-15 ng/L range that

4 is below discharge requirements for this system.

\section{Acknowledgments}

6 The information contained in this paper was developed during the course of work under Contract No.

DE-AC09-96SR18500 and DE-AC09-08SR22470 with the U.S. Department of Energy.

\section{References}

9 Clever, H., M. Iwamoto, S. Johnson and H. Miyamoto. (1987). Mercury in Liquids, Compressed Gases, 10 Molten Salts and other Elements. Pergamon Press. Oxford.

Federal Remediation Technology Roundtable (FTRT) (2002) Remediation Technologies Screening Matrix and Reference Guide, 4th Edition. U.S. Army Environmental Center. Federal Remediation

14 Technologies Roundtable. Aberdeen Proving Ground, MD 21010-5401.

Fu, F. and Q. Wang (2011). “Removal of heavy metal ions from wastewaters: A review.” Journal of Environmental Management, 92, 407 - 418. DOI: 10.1016/j.jenvman.2010.11.011

Gokel, G.W. (2003). Dean's Handbook of Organic Chemistry 2nd Edition. McGraw-Hill Publishing. 20 New York, New York.

Hozalski, R.M., E. Esbri-Amador, and C.F. Chen (2005). 'Comparison of Stannous

Chloride and Phosphate for Lead Corrosion Control.” Journal AWWA, 97(3), 89-103.

Jackson, D. G., M. E. Denham and B. B. Looney (2006). “A Framework for the Transport and Release of Mercury from DNAPL.” Remediation of Chlorinated and Recalcitrant Compounds - 2006.

27 Proceedings of the Fifth International Conference on Remediation of Chlorinated and Recalcitrant Compounds, ISBN 1-57477-157-4, May22-25 2006, Monterey, California. 
SRNL-STI-2013-00409

2 Kavanaugh, M. C. and T. R. Trussell (1980). "Design of Aeration Towers to Strip Volatile

3 Contaminants from Drinking Water,” Journal AWWA, 72(12), 684-692.

5 Klasson, K. T., K. Kosny, S. R. Drescher, G. R. Southworth, and J. F. Hensley (2003). "Reaching parts

6 per trillion clean-up criterion for mercury in water,” Waste Management 2003 Symposium, February

7 23-27, 2003, Tucson, Arizona USA.

9 Lide, D. R. (editor) (2000). CRC Handbook of Chemistry and Physics, $81^{\text {st }}$ Edition. CRC Press. Boca 10 Raton, Florida.

11

12 Lockheed Martin Inc. (1996). “Mercury Abatement Report on the U.S. Department of Energy`s Oak 13 Ridge Y-12 Plant. Fiscal Year 1996,” Technical Report Y/ER-277. Oak Ridge Y-12 Plant. Oak Ridge, 14 TN. DOI: 10.2172/419118.

Looney, B. B., M. E. Denham Jr., K. M. Vangelas, and N. S. Bloom (2003). "Removal of Mercury from 17 Low-Concentration Aqueous Streams Using Chemical Reduction and Air Stripping,” J. Environmental 18 Eng., 129(9), 819-825.

Montgomery, J. M. (1985) Water Treatment Principles \& Design, John Wiley \& Sons, New York, 23721261.

Roberts, P. V., G. D. Hopkins, C. Munz, and A. H. Riojas (1985). “Evaluating Two-Resistance Models 24 for air stripping of volatile organic contaminants in a countercurrent, packed column. Environ. Sci.

25 Technol. 19, 164-173.

27 Schwarzenbach, R., P. Gschwend and D. Imboden (1993). Environmental Organic Chemistry. New 28 York, NY, John Wiley \& Sons, Inc.

30 Southworth, G. R., S. C. Brooks, M. Peterson, M.A. Bogle, C. Miller, M. Elliott, L. Liang (2009).

31 “Controlling Mercury Release from Source Zones to Surface Water: Initial Results of Pilot Tests at the 
SRNL-STI-2013-00409

1 Y-12 National Security Complex.” Technical Report ORNL/TM-2009/035. Oak Ridge National

2 Laboratory, Oak Ridge, TN. DOI: 10.2172/969971.

4 Southworth, G. R., M. A. Bogle, S. C. Brooks, L. Liang, M. J. Peterson, B. P. Spalding, D. B. Watson,

5 T. J. Abraham (2010). Evaluation of New Options for Reducing Mercury Release at the Y-12 National

6 Security Complex. Technical Report ORNL/TM-2010/33. Oak Ridge National Laboratory, Oak Ridge,

$7 \quad$ TN. DOI: $10.2172 / 1009915$.

9 Treybal, R. E. (1980). Mass-Transfer Operations, 3rd ed., McGraw-Hill, New York, pp. 275-313.

11 U.S. Environmental Protection Agency (US EPA) (1994). “Water Quality Standards Handbook.” Rep. 12 No. EPA-823-B-94-005 a \& b. Washington, DC.

14 US EPA (1995). “Final Water Quality Guidance for the Great Lakes System.” CFR 60 FR 15366. Issued 15 March 23, 1995. Washington, DC.

US EPA (2000). “Identification of Approved and Disapproved Elements of the Great Lakes Guidance 18 Submissions From the States of Michigan, Ohio, Indiana, and Illinois, and Final Rule.” 40 CFR Part 132. Issued September 5, 2000. Washington, DC.

US EPA (1996). “Sampling Ambient Water for Trace Metals at EPA Water Quality Criteria Levels.” Rep. No. EPA-821-R-96-008. Washington, DC.

US EPA (2001). “Water Quality Criterion for the Protection of Human Health: Methylmercury.” Rep. 26 No. EPA-823-R-01-001. Washington, DC.

US EPA (2002). “Method 1631, Revision E: Mercury in water by oxidation, purge and trap, and cold vapor atomic fluorescence spectrometry.” Rep. No. EPA-821-R-02-019. Washington, DC.

US EPA (2007). Treatment Technologies for Mercury in Soil, Waste, and Water. August 2007. Rep. No. EPA-542-R-07-003. Washington, DC. http://clu-ibn.org/542R07003. 
1

2 US EPA (2010) “Guidance for Implementing the January 2001 Methylmercury Water Quality

3 Criterion.” Rep. No. EPA-823-R-10-001. Washington, DC 20460.

4 
2 Table 1: Reported Values of Vapor Pressure and Solubility used to Calculate Henry's Constant.

\begin{tabular}{|l|c|}
\hline \multicolumn{1}{|c|}{ At $\mathrm{T}=300 \mathrm{~K}$} & $\operatorname{Hg}(0)$ \\
\hline Vapor Pressure (atm) & $2.63 \mathrm{e}-06(1)$ \\
\hline Solubility (moles/L) & $3.01 \mathrm{e}-07(2)$ \\
\hline
\end{tabular}

Sources:

\begin{tabular}{|c|c|}
\hline $\mathrm{K}_{\mathrm{H}}\left(\mathrm{atm} \mathrm{L} \mathrm{mole}^{-1}\right)$ & 8.7 \\
\hline $\mathrm{K}_{\mathrm{H}}^{\prime}(-)$ & 0.36 \\
\hline
\end{tabular}

(1) Vapor Pressure Mercury, (Gokel 2003)

(2) Mercury in Water, (Clever 1987)

Table 2: Dose Rate and Injection Parameters applied during Dose-Response Test.

\begin{tabular}{|c|c|c|c|c|}
\hline Run & $\begin{array}{c}\text { Dose Rate } \\
(\mathbf{m g} / \mathrm{min})\end{array}$ & $\begin{array}{c}\mathrm{SnCl}_{\mathbf{2}} \mathrm{H}_{\mathbf{2}} \mathbf{O} \\
(\mathbf{m g} / \mathrm{L})\end{array}$ & $\begin{array}{c}\text { Inj. Flow } \\
(\mathbf{m l} / \mathbf{m i n})\end{array}$ & $\begin{array}{c}\text { Dose } \\
\text { Factor }^{(\mathbf{1})}\end{array}$ \\
\hline$\# 1$ & 0.27 & 10 & 26.6 & 0.64 \\
\hline$\# 2$ & 0.53 & 10 & 53.2 & 1.2 \\
\hline$\# 3$ & 1.33 & 50 & 26.6 & 3.0 \\
\hline$\# 4$ & 2.66 & 50 & 53.2 & 6.3 \\
\hline$\# 5$ & 6.65 & 250 & 26.6 & 16 \\
\hline$\# 6$ & 13.3 & 250 & 53.2 & 30 \\
\hline$\# 7$ & 26.6 & 1000 & 26.6 & 60 \\
\hline$\# 8$ & 53.2 & 1000 & 53.2 & 124 \\
\hline 4 & 133 & 2500 & 53.2 & 297 \\
\hline
\end{tabular}

9

(1) Dose factor based upon observed inlet wastewater conditions. Average wastewater flow rate 1,613 lpm (426 gpm) and mercury concentration $\mathrm{C}_{0}=238.9 \pm 2.47 \mathrm{ng} / \mathrm{L}(\mathrm{n}=27)$. 
SRNL-STI-2013-00409

\section{List of Figures}

3 Figure 1: Air Stripper Schematic, Operational Parameters, and Sample Location Key: inlet ( $\square$ square), 4 top of column/inlet to first packed bed ( $\Delta$ delta), middle of column/between packed beds ( $O$ circle), and 5 bottom of column/discharge of second packed bed ( $\nabla$ gradient).

7 Figure 2: Results from a 6-hour feasibility test to evaluate the removal of mercury using chemical 8 reduction and air stripping. Test Parameters: Average Inlet Concentration $=233 \mathrm{ng} / \mathrm{L}$, Wastewater $9 \quad$ Flow $=460 \mathrm{gpm}$, Air Flow $=2000 \mathrm{cfm}$, Stannous Chloride Dose $=11.8 \mathrm{mg} / \mathrm{min}$.

11 Figure 3: Effect of stannous chloride dose rate on promoting the removal of mercury using air stripping. 12 Test Parameters: Average Inlet Concentration $=239$ ng $/ \mathrm{L}$, Wastewater Flow $=426$ gpm, Air Flow $=$ $132000 \mathrm{cfm}$.

14

15 Figure 4: Difference in Concentration for nine dose factors. Tukey-Kramer minimum significant 16 difference is 11.48 . Shown is the Mean $\pm 95 \%$ Confidence Intervals. 


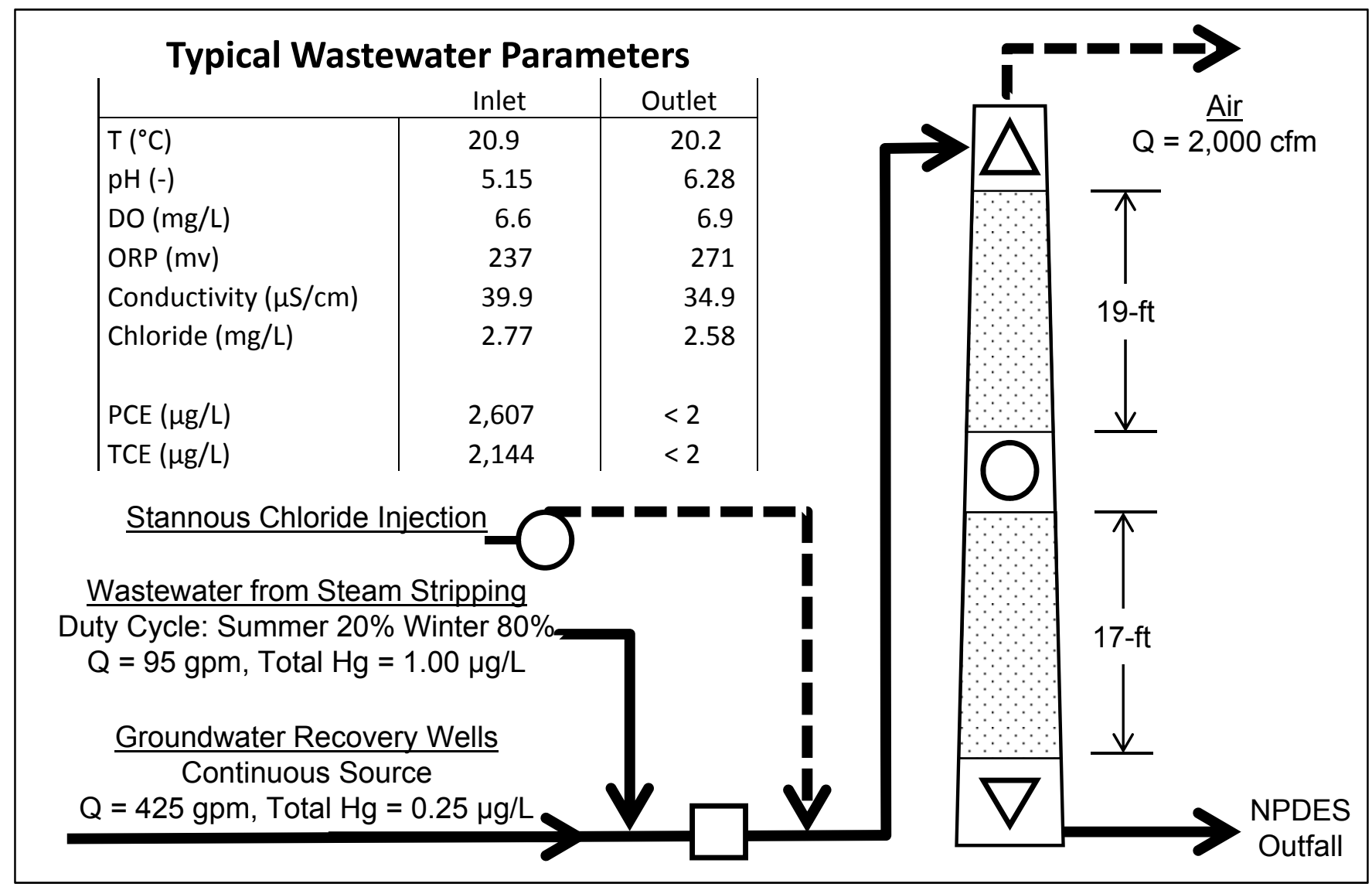




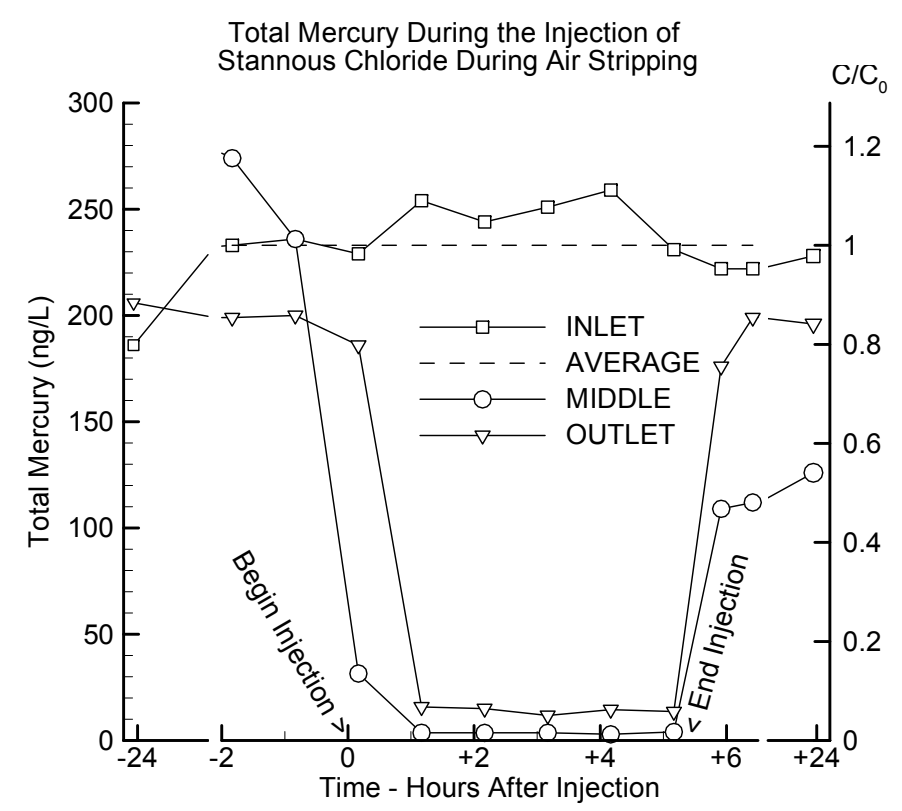




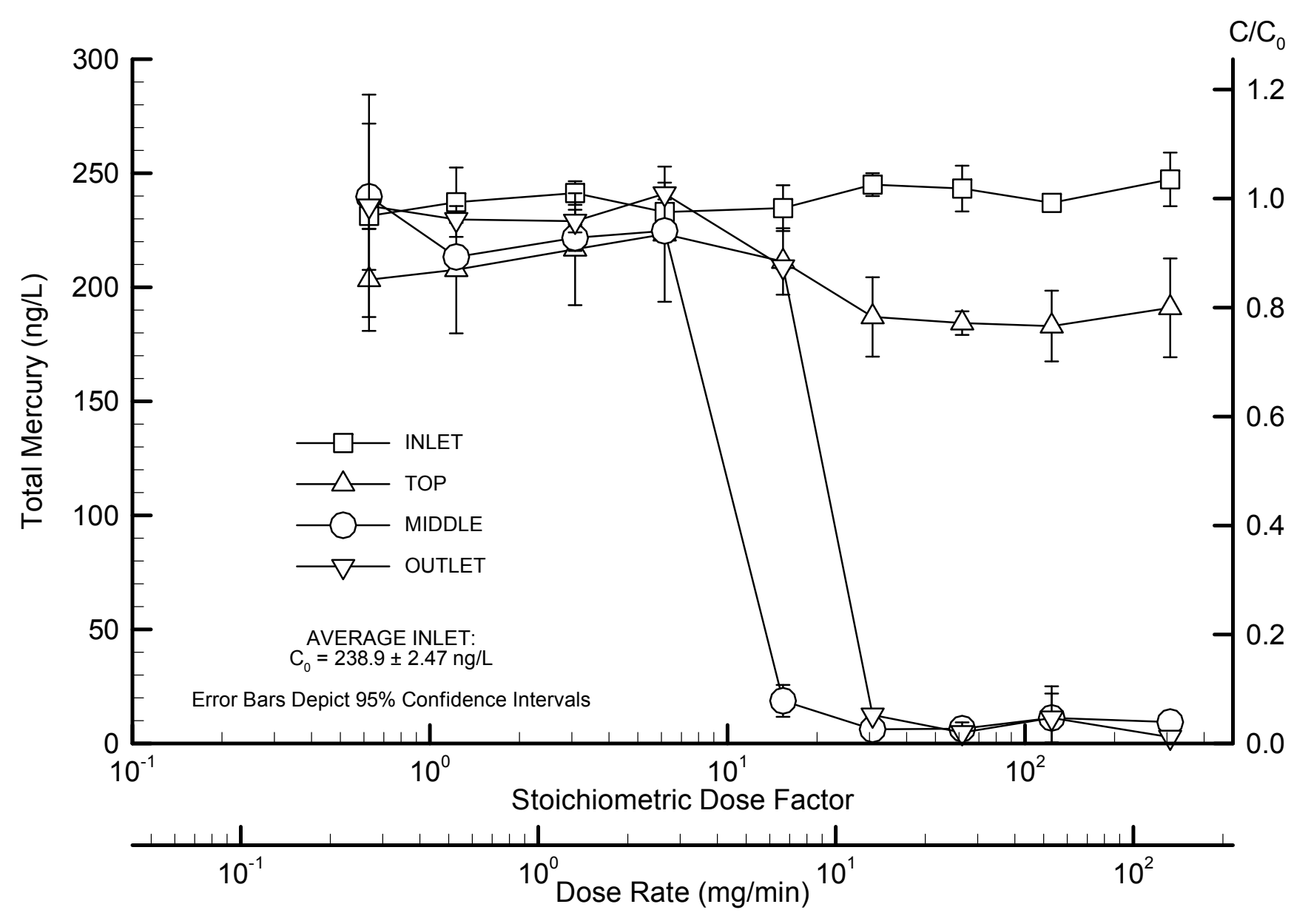




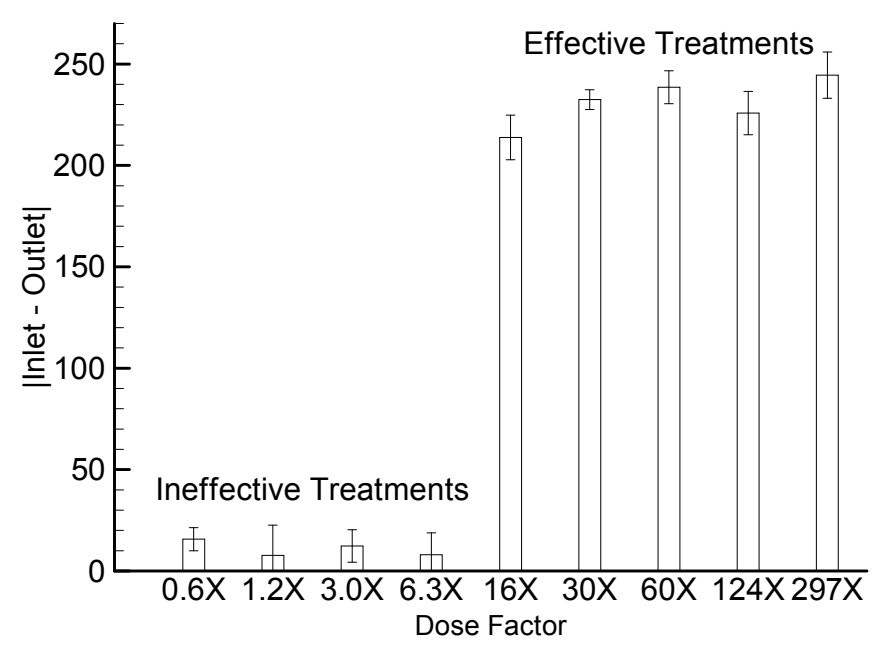

